\title{
MARCO REGULATÓRIO DA INVESTIGAÇÃO ENVOLVENDO SERES \\ HUMANOS E AS PESQUISAS CLÍNICAS NO BRASIL: O LEGISLADOR ENTRE \\ PROIBIÇÃO DE PROTEÇÃO EXCESSIVA E PROIBIÇÃO DE PROTEÇÃO \\ INSUFICIENTE
}

\section{${ }^{1}$ Selma Rodrigues Petterle}

\section{RESUMO}

Tendo como fio condutor o problema de saber se o direito penal pode trazer respostas adequadas para as pesquisas envolvendo seres humanos, o objetivo é analisar, à luz do ordenamento jurídico, o critério da proporcionalidade, sob a veste da proibição de excesso e de insuficiência de proteção, considerados os conteúdos dos projetos de lei no Congresso Nacional, de 1988 a 2015. Assim, após um panorama geral dos projetos de lei nas duas casas do Congresso Nacional, a partir de pesquisa documental, foram tecidas algumas reflexões críticas, a partir da realidade brasileira.

Palavras-chave: Marco regulatório, Investigação, Seres humanos, Brasil

\section{MARCO DE REGULACIÓN DE LA INVESTIGACIÓN INVOLUCRANDO SERES HUMANOS Y INVESTIGACIÓN CLÍNICA EN BRAZIL: EL LEGISLADOR ENTRE LA PROHIBICIÓN DEL EXCESO Y LA PROHIBICIÓN DE PROTECCIÓN DEFICIENTE}

\section{RESUMEN}

Tomando como guía la cuestión de si el derecho penal puede aportar respuestas apropiadas en el ámbito de la investigación científica involucrando seres humanos, el propósito es examinar, a la luz del ordenamiento jurídico, el criterio de proporcionalidad sob diversa óptica, la prohibición de exceso y prohibición de protección deficiente, considerado el contenido de los proyectos de ley en el Congreso Nacional entre 1988 y 2015. Por lo tanto, después de trazar una visión general de los proyectos de ley en ambas cámaras del Congreso, desde la investigación documental, fue elaborarada uma reflexión crítica, a partir de la realidad brasileña.

Palabras-claves: Marco de regulación, Investigación, Seres humanos, Brasil

\footnotetext{
1 Doutora em Direito pela Pontifícia Universidade Católica - PUCRS, Rio Grande do Sul, Brasil. Advogada, Docente Permanente e Coordenadora Adjunta do Mestrado Acadêmico em Direito do Centro Universitário La Salle - Canoas UNILASALLE, Rio Grande do Sul, Brasil. E-mail: selma.petterle@unilasalle.edu.br (Brasil)
} 


\section{INTRODUÇÃO}

Se por um lado a expansão do conhecimento científico abre uma possibilidade, ainda imensurável, de bem estar para os seres humanos, por outro, também pode acarretar a abertura de problemáticas de grande magnitude, seja no plano individual, social ou político. Para citar apenas alguns aspectos, a discussão quanto à privacidade e a proteção de dados pessoais, quanto aos critérios, riscos e benefícios da experimentação com medicamentos, quanto aos critérios para alocação de verbas públicas nas diversas modalidades de pesquisa na área da saúde, dentre outros tantos que poderiam ser elencados, o que demanda, pela complexidade, abordagem inter e transdisciplinares que possam assegurar o uso adequado da biotecnologia aplicada à medicina. (CLOTET, 1997).

Especificamente no que diz com o consentimento informado na pesquisa (CLOTET, 1995; GOLDIM, 1999), notadamente a sua falta, no caso da pesquisa com medicamentos, já há experiências no direito comparado, tanto no âmbito da legislação estatal de países centrais quanto dos periféricos. Apenas a título ilustrativo, até porque não é objeto específico deste estudo, exemplifique-se, no âmbito europeu, a proteção jurídico-penal implementada na França (art. 223-8 do Código Penal Francês) assim como, no âmbito latino americano, o México, na Ley General de Salud (LUZ, 2015). Em que pese esses panoramas em que se buscou a tutela do direito penal, o que tema provoca discussões recorrentes e controvertidas.

Tendo como fio condutor o problema de saber se o direito penal pode trazer respostas adequadas na esfera das pesquisas científicas envolvendo seres humanos, o objetivo deste artigo é analisar, à luz do ordenamento jurídico-constitucional brasileiro, o critério da proporcionalidade, sob outras vestes, qual seja, a da proibição de excesso de proteção pelas autoridades estatais e também o da proibição de insuficiência de proteção, considerados os conteúdo dos projetos de lei sobre a matéria no Congresso Nacional, desde o ano de 1988 até o ano de 2015.

Assim, após traçar um panorama geral dos conteúdos dos projetos de lei nas duas casas do Congresso Nacional, a partir de pesquisa documental nas bases de dados oficiais do legislativo, partiu-se para uma reflexão crítica acerca da busca de uma proteção na esfera penal relativamente ao tema, para ao final tecer algumas notas conclusivas sobre o tema, a partir da realidade brasileira. Ainda no plano metodológico cabe explicitar as razões desse marco temporal, que se deve primeiramente à análise da questão tendo a Constituição 
brasileira de 1988 como fundamento de validade, assim como a atuação de um órgão estatal específico, o Conselho Nacional de Saúde, órgão colegiado integrante da estrutura do Ministério da Saúde, que até então tem atuado na regulação das pesquisas no Brasil, isso desde a Resolução no 1/1988 (aqui abrangendo apenas algumas pesquisas específicas, na área da saúde, como a pesquisa com novos medicamentos), atuação que tomou um âmbito bem mais alargado em 1996, quando foram estabelecidas as normas e diretrizes para as "pesquisas envolvendo seres humanos" no Brasil (Resolução no 196/1996), âmbito novamente ainda mais alargado em 2012 (Resolução no 466/2012), atualmente em vigor.

Anote-se que a referida autoridade administrativa ampliou sobremaneira o espectro das matérias reguladas, demarcando-se, neste estudo, a identificação de três marcantes períodos. O primeiro período, de 1988 a $1996^{1}$, abrangeu apenas algumas pesquisas na área da saúde (pesquisa com novos fármacos e novos recursos profiláticos, diagnósticos, terapêuticos e de reabilitação), realizadas por pesquisadores da área da saúde habilitados e com experiência na respectiva área de pesquisa e com envolvimento direto de seres humanos, pesquisa essa que só poderia iniciar após a (necessária) autorização do Comitê de Ética em Pesquisa das Instituições de Saúde (CEP), observados os demais requisitos, como o consentimento (à época denominado de pós-informado) na forma escrita. Já no segundo período, 1996 a $2012^{2}$, o modelo deixa de ser o modelo CEP anterior, para se configurar o novo modelo CEP-CONEP. O Conselho Nacional de Saúde cria um novo órgão, a CONEP (Comissão Nacional de Ética em Pesquisa) e lhe confere atribuições. Neste segundo momento foram abrangidas todas as pesquisa envolvendo seres humanos, definidas como aquelas pesquisas que individual ou coletivamente envolvam o ser humano, de forma direta ou indireta, em sua totalidade ou partes dele, incluindo manejo de informações e materiais. Vejase, pelo teor da matéria regulada, que poucas são as áreas do conhecimento humano que não se enquadrariam nesse âmbito, face às mais diversas áreas pensarem a condição humana, aqui abrangendo também as ciências humanas e sociais. Paralelamente, em 2002 foi criada uma base de dados virtual administrada pela autoridade administrativa e disponível na internet,

\footnotetext{
${ }^{1}$ Resolução CNS 196/1996, Art. $1^{\circ}$ - Esta Resolução tem por objetivo normatizar a pesquisa na área de saúde. É de aplicação em todo o território nacional e suas disposições são de ordem pública e interesse social. Art. $4^{\circ}$ Toda pesquisa em que o ser humano for submetido a estudo, deverá prevalecer o critério de respeito à sua dignidade e à proteção de seus direitos e bem-estar.

2 Resolução CNS 196/1996, item II.2: "Pesquisa envolvendo seres humanos - pesquisa que, individual ou coletivamente, envolva o ser humano, de forma direta ou indireta, em sua totalidade ou partes dele, incluindo o manejo de informações ou materiais".
} 
para propositura dos projetos perante o CEP/CONEP e para divulgação, ao público em geral, dos projetos aprovados: o SISNEP, Sistema Nacional de Informação sobre Ética em Pesquisa Envolvendo Seres Humanos. Embora essa (aparente) transparência, o Brasil continuava em mora com a Organização Mundial da Saúde (OMS), na medida em que ainda não tinha se integrado, durante esse período, à plataforma internacional da OMS, relativamente aos ensaios clínicos (BRASIL, 2009). Ou seja, concomitantemente excesso de informação (sobre todas as pesquisas que de alguma forma envolvem seres humanos) e falta de informação sobre ensaios clínicos diretamente com seres humanos.

Para corrigir esses problemas, a autoridade administrativa (CNS), e aqui inicia o terceiro período, revisou o modelo CEP/CONEP, através da Resolução 466/2012 e criou um a nova base de dados virtual e pública: a Plataforma Brasil, implementada em $2012^{3}$. Houve novo alargamento da matéria regulada, para abranger a pesquisa envolvendo seres humanos, entendida como aquela pesquisa que de alguma forma envolve seres humanos, inclusive $\operatorname{dados}^{4}$. Ademais, expressamente (porque implicitamente o modelo anterior já assim o exigia) restou estabelecido (item XIII.3) que "As especificidades éticas das pesquisas nas ciências sociais e humanas e de outras que se utilizam de metodologias próprias dessas áreas serão contempladas em resolução complementar, dadas suas particularidades". Ou seja, a longa manus do Conselho Nacional de Saúde veio para ficar, em todas as áreas do conhecimento humano.

\section{O CONGRESSO NACIONAL E OS PROJETOS SOBRE A MATÉRIA, DESDE 1996 ATÉ 2015: GUINADAS DE CENTO E OITENTA GRAUS}

De 1988 a 2015 foram propostos vários projetos de lei com conteúdo vinculado à matéria. Considerando os três períodos mencionados anteriormente, eis o perfil, em bloco, dos projetos de lei.

No primeiro período foram propostos dois (2) projetos de lei, ambos de iniciativa do Senado Federal. O PLS 323/1991, do Senador Francisco Rollemberg, buscou estabelecer normas e requisitos para a pesquisa médica em seres humanos, projeto que não foi adiante na

\footnotetext{
${ }^{3}$ Em 2011 foi efetivamente implementada a nova base de dados, inicialmente denominada de REBRAC (BRASIL, 2009). e rebatizada de REBEC, Registro Brasileiro de Ensaios Clínicos (BRASIL, 2010).

${ }^{4}$ Resolução CNS 466/1996, item II.14 - "pesquisa envolvendo seres humanos - pesquisa que, individual ou coletivamente, tenha como participante o ser humano, em sua totalidade ou partes dele, e o envolva de forma direta ou indireta, incluindo o manejo de seus dados, informações ou materiais biológicos".
} 
discussão, tendo sido arquivado ao final da legislatura. No ano seguinte aconteceu nova propositura, agora do Senador César Dias, para, através do PLS 25/1992, projeto ao estilo xenófobo, arquivado ao final da legislatura, que pretendeu proibir no Brasil os ensaios clínicos de fases I e II, nos testes de fármacos produzidos por tecnologias estrangeiras.

Já o segundo período, na vigência da Resolução CNS 196/1996, os sete (7) projetos de lei têm um perfil bastante peculiar, pois todos chancelam o modelo cunhado pelo Conselho Nacional de Saúde (modelo CEP/CONEP) para as pesquisas envolvendo seres humanos. Três (3) propostas partiram da Câmara dos Deputados, um (1) do Executivo e três (3) do Senado Federal. Na Câmara dos Deputados foi proposto, em 2002, o PL 7.086/2002, de iniciativa do Deputados Federal Ivan Paixão(PPS/Sergipe), que estabelece normas regulamentadoras para as pesquisas envolvendo seres humanos ${ }^{5}$, definindo direitos e deveres no que diz com essas pesquisas, em síntese chancelando a autoridade do sistema CEP/CONEP, aportando um aspecto novo, que é a criminalização de condutas na pesquisa envolvendo seres humanos (art. 35), a saber: "expor a vida ou a saúde do sujeito da pesquisa a perigo direto ou iminente diverso dos riscos previsíveis da pesquisa", "realizar pesquisa sem contar com o consentimento livre e esclarecido do sujeito da pesquisa e/ou de seu representante legal", “deixar de comunicar às autoridades sanitárias os resultados da pesquisa, sempre que os mesmos puderem contribuir para a melhoria das condições de saúde da coletividade"

No ano seguinte foi proposto, pelo Deputado Colbert Martins, o PL 2.473/2003, que replicou a posição similar ao projeto anterior, igualmente chancelando a autoridade do sistema CEP/CONEP, tipificando novos tipos penais (também no art. 35), no mesmo sentido do

\footnotetext{
${ }^{5}$ PL 7.086/2002, art. 3, III" Pesquisa envolvendo seres humanos - pesquisa que, individual ou coletivamente, envolva o ser humano, em sua totalidade ou partes dele, incluindo o manejo de informações ou materiais ${ }^{6}$ PL 7.086/2002, Art. 35 (projeto arquivado em 2003):

I - Expor a vida ou a saúde do sujeito da pesquisa a perigo direto ou iminente diverso dos riscos previsíveis da pesquisa. Pena: detenção, de 6 (seis) meses a 3 (três) anos, se o fato não constitui crime mais grave.

II - Realizar pesquisa sem contar com o consentimento livre e esclarecido do sujeito da pesquisa e/ou de seu representante legal. Pena: reclusão, de 4 (quatro) a 6 (seis) anos

III - Deixar de comunicar às autoridades sanitárias os resultados da pesquisa, sempre que os mesmos puderem contribuir para a melhoria das condições de saúde da coletividade.

Pena: reclusão de 1 (um) a 4 (quatro) anos, e multa.

$\S 1^{\circ}$ As penas previstas neste artigo serão aumentadas de um terço se o crime é praticado contra sujeitos vulneráveis de pesquisa.

$\S 2^{\circ}$ Além das penas privativas de liberdade e de multa, podem ser impostas, cumulativa ou alternadamente, observado o disposto nos artigos 44 a 47 do Código Penal:

I - a interdição temporária de direitos;

II - a prestação de serviços à comunidade.

$\S 3^{\circ} \mathrm{O}$ Promotor e o Patrocinador que, de qualquer forma, omissiva ou comissiva, concorrer para os crimes referidos neste artigo, ficarão sujeitos, sem prejuízo de outras sanções penais ou cíveis, a pena pecuniária, fixada em dias-multa, correspondente ao mínimo e ao máximo de dias de duração da pena privativa da liberdade cominada ou crime, e observado o disposto no art. $60, \S 1^{\circ}$, do Código Penal.
} 
projeto anterior. No substitutivo da Deputada Cida Diogo, posteriormente arquivado, houve significativa redução dos aspectos regulados, se limitando a cinco artigos, unicamente com as atribuições do Conselho Nacional de Saúde, da CONEP e da ANVISA, extirpados os novos tipos penais.

Nos anos posteriores ${ }^{7}$ foram propostos o PL 3.497/2004 e o PL 6.032/2005, não direcionados a regular tais pesquisas, mas sim a criar um órgão consultivo de âmbito nacional, para discutir as complexas questões postadas pela biomedicina. Em 2006, com o PLS $78 / 2006^{8}$, o Senado Federal, via iniciativa do Senador Cristóvão Buarque, também chancela o modelo CEP/CONEP e ressuscita a discussão sobre a criminalização de novas condutas, estabelecendo punições no caso de violação das diretrizes e normas concernentes às pesquisas envolvendo seres humanos. Especificamente quanto aos crimes, busca tipificar as seguintes condutas humanas: "conduzir pesquisa que envolve seres humanos em desacordo com o termo de consentimento ou o protocolo" e "causar ou permitir que ocorram danos ou prejuízos injustificados a qualquer sujeito da pesquisa". Estabeleceu, ademais, a coresponsabilidade (tanto do pesquisador, quanto do patrocinador, assim como da instituição) pela indenização devida aos sujeitos das pesquisas por eventuais danos ou prejuízos. No ano de 2007 o Senador Flávio Arns propõe o PLS 396/2007, arquivado em 2011, que ataca outra frente bem especifica, a dos ensaios clínicos com medicamentos experimentais, qual seja, a questão relativa à continuidade no fornecimento da intervenção após o término do estudo (responsabilidade pós-pesquisa), determinando a obrigatoriedade de fornecimento, ao sujeito de pesquisa que participou de pesquisa com fármacos (com nova formulação ou nova combinação de fármacos), com fornecimento gratuito pela instituição pesquisadora (durante a pesquisa até a efetiva comercialização) e pelo fabricante (quando o fármaco já for comercializado).

\footnotetext{
${ }^{7}$ O PL 3.497/2004, de iniciativa do Deputado Ivan Valente e da Deputada Maninha, para criar uma Comissão Nacional de Bioética, como órgão consultivo vinculado à Presidência da República, ao qual foi apensado o PL 6.032/2005, de iniciativa do Poder Executivo, para criar o Conselho Nacional de Bioética no Brasil (CNBioética), para os quais já foram constituídas duas comissões especiais e que, face ao término da Legislatura, aguarda constituição de uma nova comissão especial.

${ }^{8}$ PLS 78/2006, Art. 8: Conduzir pesquisa que envolve seres humanos em desacordo com o termo de consentimento ou o protocolo aprovado:

Pena - detenção, de 1 (um) a 3 (três) meses, e multa.

Art. 9: Causar ou permitir que ocorram danos ou prejuízos injustificados a qualquer sujeito da pesquisa: Pena - detenção, de 3 (três) meses a 1 (um) ano, e multa.

Agrava-se a pena: I - da $1 / 2$ até $2 / 3$, se resultar lesão corporal de natureza grave no sujeito da pesquisa; II - de $2 / 3$ até o dobro, se resultar a morte do sujeito da pesquisa."
} 
No terceiro período, o Senado Federal toma rumo na busca de regulação por lei apenas das pesquisas clínicas no Brasil, e não das pesquisas envolvendo seres humanos, como amplamente definido pelo Conselho Nacional de Saúde, o que, por si só, já demonstra uma preocupação mais centrada, pelas razões que serão analisadas no item seguinte. Trata-se do PLS 200/2015, proposto em abril de 2015, pelos Senadores Ana Amélia Lemos, Waldemir Moka e Walter Pinheiro, com projeto substitutivo oferecido no dia 16.12.2015, na Comissão de Ciência, Tecnologia, Inovação, Comunicação e Informática. Pela extensão do projeto, é inviável a análise de seu conteúdo nesta oportunidade, cabendo referir minimamente que visa abarcar linhas gerais, mais sistematizadas, para esse marco regulatório, em que pese uma série de aspectos problemáticos a serem enfrentados nas discussões, durante o processo legislativo, a saber: a) fragilidade da garantia de transparência (art. 6, III), na medida em que não estabelece uma conformação mínima para a base de dados pública constante no art. 38, e nem mesmo uma sanção para a ausência desse registro; b) extrema exigüidade dos prazos para análise dos documentos acostados (configurando checagem tácita em 5 dias) e para a análise ética dos projetos (art. 14 e art. 15); c) exceções à vedação de remuneração (art. 20, §2) pouco protetivas, em síntese admitindo remuneração para ensaios clínicos sabidamente de maior risco (fase 1); d) prazo de armazenamento dos documentos de no mínimo 5 anos para o pesquisador (art. 26, XIII), de até 3 anos do término para o CEP (art. 13, § único) e sem prazo estipulado para o patrocinador: incongruência, se consideradas as responsabilidades; e) continuidade do tratamento pós-ensaio clínico sob responsabilidade do patrocinador (art. 30): determinação praticamente inócua, na medida em que estabelece a possibilidade de interrupção se o produto estiver regulamente comercializado (inciso $\mathrm{V}, \S 3$, ); f) normas organizacionais e procedimentais para o CEP: delineamento mínimo e precário, na medida em que estipula apenas número mínimo de sete membros (art. 9), desacompanhado de norma sobre quorum presencial (salvo uma mera referência a quorum mínimo a ser estipulada em procedimentos operacionais padrões de cada CEP) e modalidade de deliberação (se consenso, se votação, maioria simples ou outra).; g) não apenas a inexistência de qualquer mecanismo legal para proteção de pacientes em situação de emergência (art. 18, §6), como a sua chancela sem consentimento, impondo-se apenas informar a posteriori, para decisão quanto à permanência na pesquisa.

Já na Câmara dos Deputados, foram duas propostas legislativas, uma de julho de 2015, o PL 2.173/2015, do Deputado Federal Celso Jacob, projeto de lei que pretende alterar o Código Civil brasileiro de 2002, na parte que trata dos direitos de personalidade (art. 13), para expressamente incluir, desde que gratuita, uma permissão de uso do próprio corpo com objetivo exclusivamente científico, proteção que está implicitamente abarcada, já que o nosso 
sistema jurídico não enuncia um elenco fechado de direitos de personalidade, seja na Constituição, seja no Código Civil, consagrando uma cláusula geral de tutela da personalidade e do livre desenvolvimento da pessoa humana (PINTO, 2004; PINTO, 1999; TEPEDINO, 2001, SARLET e PETTERLE, 2010).

Refira-se ainda a proposta legislativa veiculada no PL 3.454/2015 (Deputado Welinton Prado), de 28 de outubro de 2015, que dispõe sobre a fabricação, produção e a distribuição da fosfoetanolamina sintética aos pacientes com câncer, que deverá ser garantida pela União, em larga escala e pelo tempo necessário, fornecimento que estará condicionado à assinatura de um termo (denominado de "Termo de Responsabilidade") de que a pessoa que ingerir o referido produto tem ciência de "que não há testes clínicos realizados que garantam o fim terapêutico esperado ou de efeitos colaterais" e de que a substância não é um medicamento e não substitui quaisquer medidas outras já cientificamente comprovadas para o tratamento do câncer (como exames, cirurgias, quimioterapia, radioterapia e outros).

Com certeza a busca da cura do câncer traz à tona uma série de argumentos de ordem racional (calcados em pesquisa científica corretamente delineada e realizada em bases éticas) e emocional (desespero de pacientes no caso de doenças graves e também de doenças para as quais não se conhece tratamento) que são difíceis de equacionar. A judicialização do caso da fosfoetanolamina no Brasil (que não será aqui abordada e que motivou inclusive a propositura do referido projeto de lei) evidencia, isso sim, é a premente necessidade de um marco regulatório específico para as pesquisas clínicas no Brasil, pois o problema não está em resolver como será o perfil das pesquisas clínicas com fosfoetanolamina sintética no Brasil (e o seu financiamento) e sim quais os órgãos e quais os procedimentos para aprovação dessas pesquisas e de outras tantas similares. A questão está em definir normas organizacionais e procedimentais para a pesquisa clínica, garantindo que as pesquisas aconteçam, em bases eticamente aceitáveis.

Veja-se que essa equipe de pesquisadores da área da química, que conseguiu patentear no Brasil a fosfoetanolamina sintética (INPI, 2015), aprovou via sistema CEP-CONEP apenas um único estudo sobre a fosfoetanolamina como suplemento alimentar, no ano de 2007 (SISNEP, 2007). Trata-se da pesquisa intitulada "Efeito da suplementação alimentar com ácido graxo ômega-3 e fosfoetanolamina em dezenove (19) pacientes com asma brônquica", aprovado pelo Comitê de Ética em Pesquisa (CEP/UNICAMP/Faculdade de Ciências Médicas/SP), em quatro meses (ingresso no CEP dia 02/05/2007 e aprovação no dia 27/08/2007). Acrescente-se que os pesquisadores apresentaram os resultados do projeto no ano seguinte (2008), resultado que não parece muito animador, já que não foi possível afirmar 
que o fosfoetanolamina (como suplemento alimentar) teria melhorado a absorção de Ômega-3 (outro suplemento alimentar). Os pesquisadores afirmaram, ainda, que "não houve diferença estatisticamente significativa no consumo de corticóide inalado e broncodilatador de longa ação nos dois grupos” (CHIERICE, PIAI, QUAGLIATO JÚNIOR, 2008, p. 2). Ou seja, não houve diferença entre o grupo de pacientes que recebeu Ômega-3 e fosfoetanolamina e o grupo de paciente que recebeu ômega -3 e placebo.

Rastreada toda a informação nos dois sistemas oficiais de informação administrados pelo Conselho Nacional de Saúde/Ministério da Saúde, ou seja, no SISNEP, de 2002 a 2011, e na Plataforma Brasil, de 2012 a novembro de 2015 (PETTERLE, 2013), não se localizou obter qualquer outra pesquisa clínica aprovada no CEP da instituição de vínculo dos pesquisadores (CEP/CONEP CEP/UNICAMP/Faculdade de Ciências Médicas/SP). Ora, problemas regulatórios não são resolvidos com lei encomendada para uma determinada pesquisa (que evidencia um outro problema, que é o saber quais são os critérios a pautar a distribuição de verbas públicas para pesquisa científica) e sim com lei que reequacione os nós do modelo regulatório brasileiro e que efetivamente proteja os múltiplos atores presentes nesses cenários.

\section{CRIMINALIZAR CONDUTAS E PENSAR PROTEÇÃO DOS DIREITOS FUNDAMENTAIS EM UM INTERVALO ENTRE DOIS EXTREMOS, ENTRE UMA INSUFICIENTE PROTEÇÃO E UMA EXCESSIVA PROTEÇÃO: UMA TAREFA ÁRDUA}

Como visto anteriormente, vários projetos de lei concentraram esforços na definição de novos tipos penais, medida que, a considerar os diversos delineamentos da pesquisa científica, pode ser entendida, no plano jurídico, como excessivamente protetiva, se se tratar da "pesquisa envolvendo seres humanos", naquela ampla acepção já referida.

Retome-se o conteúdo consagrado no PLS 78/2006 (art. 35), que pretende tipificar como crime a conduta de "conduzir pesquisa que envolve seres humanos em desacordo com o termo de consentimento ou o protocolo aprovado". Cumpre problematizar quais seriam as razões para simplesmente adotar o amplo conceito de pesquisa envolvendo seres humanos do CNS, o que, se adotado, praticamente inviabilizaria pesquisas científicas que de alguma forma envolvessem humanos. Já no que diz com a conduta de "causar ou permitir que ocorram danos ou prejuízos injustificados a qualquer sujeito da pesquisa”, com agravantes no caso de resultar lesão corporal ou morte do sujeito da pesquisa, recorde-se que já foi contemplada proteção jurídico-penal (Código Penal Brasileiro, lesão corporal, lesão corporal de natureza grave, lesão corporal de seguida de morte, perigo para a vida ou saúde de outrem, art. 129 e 
art. 132).

Recorde-se que Resolução CNS 466/1996, do Conselho nacional de Saúde define pesquisa envolvendo seres humanos como "pesquisa que, individual ou coletivamente, tenha como participante o ser humano, em sua totalidade ou partes dele, e o envolva de forma direta ou indireta, incluindo o manejo de seus dados, informações ou materiais biológicos". Ora, praticamente todas as áreas de conhecimento enquadram-se neste amplo conceito (e não apenas as pesquisas clínicas). Frise-se que o direito penal não pode fixar uma barreira intransponível para todas as pesquisas científicas que de alguma forma envolvem ser humanos sem incorrer em excessos. Isso não significa afirmar uma completa exclusão da proteção jurídico-penal neste contexto. Qual o norte a seguir? Pode-se afirmar que existiriam casos em que a criminalização é requerida?

STRECK (2004) afirma que a liberdade de conformação do legislador, inclusive no campo do direito penal, não se norteia mais pelo paradigma liberal-iluminista. A "cláusula de proibição de proteção deficiente" (STRECK, 2004, p. 254), coloca em "xeque a liberdade de conformação legislativa em sentido contrário" (STRECK, 2004, p. 280), sendo imprescindível enxergar o duplo viés do controle de constitucionalidade das normas penais, seja em relação aos excessos legislativos, seja em relação à insuficiência de proteção.

Em geral viabiliza-se o enfrentamento do problema das restrições aos direitos fundamentais nos Estados Democráticos de Direito mediante aplicação do princípio da proporcionalidade, como um dos critérios de controle das medidas restritivas de direitos fundamentais, análise que se dá sob a perspectiva de seus três subprincípios: adequação (ou idoneidade) necessidade e proporcionalidade em sentido estrito (ALEXY, 1997; ALEXY, 2002; CANOTILHO, 2004; MIRANDA, 2000; PULIDO, 2003; SARLET, 2009; SARLET, 2004). Face à complexidade de examinar todos esses aspectos, desenvolveu-se um outro olhar acerca da proporcionalidade, sob outras vestes, qual seja, a da proibição de excesso de proteção pelas autoridades estatais e também a da proibição de insuficiência de proteção dos direitos fundamentais (CANARIS, 2003). Anote-se que a constante busca de racionalidade durante o processo de aplicação do teste de proporcionalidade levou o Tribunal Constitucional Alemão, após a decisão do ano de 1975 sobre a interrupção voluntária da gravidez, a acolher, no ano de 1993 (SCHWABE, 2003), essa outra perspectiva da proporcionalidade (proibição da insuficiência de proteção).

Sob essa ótica, CANOTILHO (2004, p. 273) destaca tanto o controle dos excessos quanto o controle da insuficiência de proteção, esta consubstanciando uma proibição de que os poderes públicos adotem medidas insuficientes no que tange aos deveres estatais de proteção dos direitos fundamentais, deixando de satisfazer a exigência de uma proteção mínima, embora 
utilizando terminologia diferenciada, a da "proibição por defeito" ou do "defeito de protecção". SARLET (2004, p. 100) critica apenas a terminologia de Canotilho por entender que a expressão defeito de proteção "não traduz com precisão a idéia de proteção insuficiente". PULIDO (2003) se refere à proibição de proteção deficiente como critério para determinar a violação de um direito fundamental, por omissão Estatal, no que tange aos seus deveres de proteção, advertindo que esta versão do princípio da proporcionalidade tem peculiaridades quanto à estrutura argumentativa, notadamente porque o objeto de controle é distinto.

Aqui se verifica a complexidade do problema de pensar a proteção dos direitos fundamentais em um intervalo entre dois extremos, entre uma insuficiente proteção de um direito fundamental (aquém do mínimo de proteção exigível) e uma excessiva proteção de um direito fundamental (além do máximo de proteção exigível) limites extremos que indicam ou uma omissão dos poderes públicos (ou atuação insuficiente destes) ou uma atuação excessiva dos mesmos, ambas violadoras dos direitos fundamentais.

Nesse contexto é muito relevante a distinção entre gênero e espécie. Advirta-se: pesquisa com seres humanos (e aqui entra o universo da pesquisa clínica) é uma espécie do gênero "pesquisa envolvendo seres humanos". Para a categoria ampla (o gênero "pesquisa envolvendo seres humanos") há que se afirmar que não existem casos em que a criminalização seria requerida, Ou seja, a resposta é negativa, na medida em que existem muitos outros meios de (efetiva) proteção a serem pensados pelo legislador. Exemplos? Reestruturar o modelo regulatório brasileiro, conferindo atribuições de análise e aprovação desses projetos, no plano ético e científico, apenas internamente às instituições de vínculo do pesquisador (nos Comitês institucionais de ética em pesquisa ou outros órgãos criados para tanto). Atribuir a esses comitês a função de acompanhamento das pesquisas em curso na instituição. Reforçar a proteção definindo uma conformação e uma infra-estrutura mínima para esses órgãos, assim como procedimentos internos, inclusive recursais.

Já para a categoria mais restrita (a espécie pesquisa clínica; pesquisa com seres humanos) a resposta penal também é, em princípio, negativa, na medida em que também poderiam ser concebidos outros mecanismos. Exemplos? Medida legislativa que estabeleça responsabilidade civil objetiva e solidária (entre patrocinador, instituição e pesquisador principal) no caso de inobservância do procedimento definido em lei que efetivamente regulasse a análise e a aprovação de pesquisas clínicas. Obrigatoriedade do patrocinador de contratar seguro de responsabilidade civil para a pesquisa clínica. Registro público obrigatório para as pesquisas clínicas. Infrações administrativas (advertência, multa, suspensão de verbas públicas para pesquisa) no caso de descumprimento do procedimento previsto em lei. Normas organizacionais rigorosas, estruturando pormenorizadamente os CEP com atribuição exclusiva análise e aprovação das pesquisas clínicas. Recorde-se, por oportuno, que já há 
instrumentos próprios para a fiscalização do exercício de atividade profissional, que são os códigos de ética profissionais. E que o descumprimento de normas éticas definidas para tal atuação pode acarretar suspensão e até mesmo cancelamento de um registro profissional.

Todavia, no caso específico das pesquisas clínicas é possível sim pensar parâmetros mais rigorosos para assegurar o (processo de) consentimento informado. Vide, a propósito, a análise de GOLDIM (1999), que constata problemas quanto ao uso do consentimento informado em projetos de pesquisa em seres humanos, a partir da análise de 59 pessoas que ingressaram em diferentes estudos no Hospital de Cínicas de Porto Alegre. Identificou-se que o texto do respectivo termo oferecia dificuldades de entendimento, exigindo nível de escolaridade maior do que o dos pesquisados. Segundo o autor, 44,1\% das pessoas autorizaram sua participação no estudo, todavia sem compreender exatamente o procedimento, os riscos ou os benefícios. É claro que a forma escrita é, em tese, um meio eficaz de garantir o direito de liberdade, de decidir por ingressar ou não na pesquisa. Ocorre que há atualmente uma banalização do documento que materializa o consentimento da pessoa (o Termo de Consentimento), exigido pelo CNS para toda pesquisa envolvendo seres humanos, que o efeito obtido parece ser exatamente o contrário do buscado: desproteção da pessoa (fazendo prova escrita pré-constituída do fato), ao invés de proteção. Cuidado: há uma sutil diferença entre exigir o consentimento da pessoa (sem definir forma) e exigir a materialização formal do consentimento da pessoa (através de termo específico), como determinado pelo CNS para qualquer pesquisa envolvendo seres humanos (conteúdo em geral reproduzido nos projetos de lei sobre a matéria).

Critérios rigorosos com relação à forma específica para esse consentimento não deveriam ser aplicados a todas e quaisquer pesquisas científicas envolvendo seres humanos. Assim, parece razoável que a legislação que regulamente a pesquisa clínica venha a estabelecer consentimento informado na pesquisa clínica com forma específica e conteúdo delimitado por lei ${ }^{9}$.

Para as pesquisas clínicas com pessoas em situação de extrema vulnerabilidade, como os pacientes em situação emergência, aqui sim há que pensar mecanismos que possam efetivamente reforçar a proteção jurídica da liberdade, através de um tipo penal específico. Exemplifique-se com a informação oficial brasileira constante na Plataforma Brasil: inseridas duas expressões, "intubados" e "ventilados", nessa base de dados, como critério de pesquisa, foram localizados vários estudos em diversos hospitais no Brasil, conforme a tabela que consta a seguir. São pesquisas clínicas de medicamentos com pacientes com diagnóstico de pneumonia e evidentemente em situação de emergência: a) com BAY 41-6551 (nova via de antibiótico, inalável); b) comparação entre TR-701 Ácido Livre e Linezolida; c) comparação 
entre Ceftolozane/Tazobactam Intravenoso e Meropenem.

\begin{tabular}{|c|c|}
\hline $\begin{array}{l}\text { PLATAFORMA BRASIL: } \\
\text { Título da Pesquisa }\end{array}$ & Instituições \\
\hline $\begin{array}{l}\text { Estudo prospectivo, randomizado, duplo-cego, } \\
\text { controlado por placebo, multicêntrico para avaliar a } \\
\text { segurança e eficácia de BAY 41-6551 como terapia } \\
\text { adjuvante em pacientes com pneumonia causada por } \\
\text { bactéria Gram-negativa, intubados e ventilados } \\
\text { mecanicamente. }\end{array}$ & $\begin{array}{l}\text { 1) Fundacao Faculdade Regional de } \\
\text { Medicina S J Rio Preto } \\
\text { 2) Sociedade Campineira De Educação E Instrução } \\
\text { 3) Santa Casa de Misericordia De Belo } \\
\text { Horizonte } \\
\text { 4) Uniao Brasileira de Educacao E } \\
\text { Assistencia }\end{array}$ \\
\hline $\begin{array}{l}\text { Protocolo TR701-132: ¿Estudo de Fase 3, } \\
\text { Randomizado, Duplo-Cego para Comparar TR-701 } \\
\text { Ácido Livre e Linezolida em Pacientes Ventilados com } \\
\text { Pneumonia Nosocomial por Bactérias Gram-Positivas ¿ }\end{array}$ & $\begin{array}{l}\text { 1) Hospital do Trabalhador/SES/PR } \\
\text { 2) Associação Hospitalar Beneficente } \\
\text { São Vicente de Paulo } \\
\text { 3) Santa Casa de Misericordia De Belo } \\
\text { Horizonte } \\
\text { 4) Fundacao Faculdade Regional de } \\
\text { Medicina S J Rio Preto } \\
\text { 5) Hospital Professor Edmundo Vasconcelos } \\
\text { 6) Hospital Vera Cruz Sa (Belo Horizonte-MG) } \\
\text { 7) Polonio Clinica de Servicos Medicos } \\
\text { em Gastroenterologia E Cirurgia } \\
\text { Toracica S/S } \\
\text { 8) Santa Casa De Misericordia De } \\
\text { Votuporanga } \\
\text { 9) Puc/ Campinas }\end{array}$ \\
\hline $\begin{array}{l}\text { Um Estudo Prospectivo, Randomizado, Duplo-Cego, } \\
\text { Multicêntrico de Fase 3, para Avaliar a Segurança e } \\
\text { Eficácia de Ceftolozane/Tazobactam Intravenoso em }\end{array}$ & $\begin{array}{l}\text { 1) Santa Casa de Misericordia De Belo } \\
\text { Horizonte } \\
\text { 2) Hospital Vera Cruz SA (Belo Horizonte-MG) }\end{array}$ \\
\hline
\end{tabular}

\footnotetext{
${ }^{9}$ Assim como ausência de forma definida para o consentimento em outras modalidades de pesquisa científica, e, inclusive caso de pesquisas em que se estabeleceria uma presunção legal de consentimento, como estudos retrospectivos, quantitativos, sem acesso a dados pessoais. Essa previsão já consta, de alguma forma, na nova legislação brasileira sobre acesso a informação (Lei 12.527/2011, especialmente art. 36, §1, I), embora como uma dispensa de consentimento, que não será exigido quando as informações forem necessárias à realização de estatísticas e pesquisas científicas de evidente interesse público ou geral, previstos em lei, sendo vedada a identificação da pessoa a que as informações se referirem.
}

\begin{tabular}{|c|c|}
\hline $\begin{array}{c}\text { PLATAFORMA BRASIL: } \\
\text { Título da Pesquisa }\end{array}$ & Instituições \\
\hline $\begin{array}{l}\text { Comparação com o Meropenem em Pacientes Adultos } \\
\text { Ventilados com Pneumonia Nosocomial - Protocolo } n^{\circ} \\
\text { CXA-NP-11-04 }\end{array}$ & $\begin{array}{l}\text { 3) Hospital Alemao Oswaldo Cruz } \\
\text { 4) Associacao Dos Funcionarios Publicos } \\
\text { do Estado Do Rgsul } \\
\text { 5) Hospital Professor Edmundo Vasconcelos } \\
\text { 6) Hospital do Trabalhador/SES/PR } \\
\text { 7) Sociedade Campineira de Educação e Instrução }\end{array}$ \\
\hline
\end{tabular}

Tabela - PLATAFORMA BRASIL - Projetos de pesquisa localizados com as expressões "intubados" e "ventilados". Fonte: Elaboração a partir dos dados extraídos da Plataforma Brasil Disponível em http://aplicacao.saude.gov.br/plataformabrasil. Acesso 20 out 2015. 
Como após a aprovação pelo sistema CEP/CONEP a informação passa a ser pública, ela é disponibilizada na Plataforma Brasil. Posteriormente caberia fazer o registro no REBEC (REBEC, Registro Brasileiro de Ensaios Clínicos, criado em 2011) ou outra base (primária) de registros. No nosso REBEC não há qualquer ensaio clínico com o termo BAY 41-6551. Infrutífera também é a tentativa de buscar informações no site da ANVISA, na área dos medicamentos, pois tamanha é a quantidade de itens formais de preenchimento obrigatório que fica completamente inviabilizada, na prática, a consulta para o público em geral. A situação também não é distinta com relação ao Protocolo TR701-132 (com o medicamento TR-701), assim como o Protocolo $\mathrm{n}^{\mathrm{o}}$ CXA-NP-11-04 (com o medicamento Ceftolozane/Tazobactam), ensaios clínicos que estão acontecendo no Brasil no corrente ano de 2015.

Nas situações elencadas indubitavelmente foram selecionadas para as pesquisas clínicas com medicamentos pessoas em evidente situação de vulnerabilidade e de emergência e, como não poderia deixar de ser, familiares também a enfrentar situações limítrofes. Como, nessas situações extremas, se daria o processo de consentimento informado, mecanismo garantidor, por excelência, da livre manifestação de vontade, no sentido de decidir ingressar, ou não, no estudo? Esse é um exemplo de situação limítrofe em que deveria ser delimitado, por lei, se seria possível e sob quais condições complementares seria possível realizar esse tipo de pesquisa, seja na situação fática em que a pessoa é incapaz de dar o seu consentimento, seja quando a própria urgência impossibilita a obtenção de qualquer autorização prévia. Se há justificativas éticas para os comitês de ética em pesquisa institucionais e a CONEP autorizarem que se faça pesquisa clínica com medicamentos experimentais em pacientes em situação de emergência (de fase 3, como os exemplificados), isso não necessariamente significa que estariam implementados níveis adequados de proteção jurídica da pessoa, de sua liberdade, de sua integridade física e psíquica. Aqui parece ser situação específica que demandaria pensar, adicionalmente aos meios já elencados, a proteção na esfera penal.

\section{CONCLUSÃO}

Vistas essas breves notas acerca dos projetos de lei no Congresso Nacional para regular as pesquisas envolvendo seres humanos (em sentido bastante amplo) e para regular as pesquisas clínicas, foram aportados alguns elementos para reflexão relativamente ao caminho tomado pelo Brasil no que diz com a regulamentação do tema: total ausência de lei em sentido formal. Há apenas atos normativos secundários exarados por autoridade pública vinculada à 
administração pública.

A regulação brasileira até então vigente está baseada unicamente em norma jurídica secundária, exarada por meio de Resolução do Conselho Nacional de Saúde, órgão que regulou todas as pesquisas que de alguma forma envolvem seres humanos, de forma direta ou indireta, individual ou coletivamente, no todo ou partes dele, dados e materiais. Ocorre que conceber estruturas para apreciar, aprovar e fiscalizar pesquisas científicas de alto risco na área da saúde (estruturas que devem atuar intensamente na fiscalização das pesquisas, dentro das instituições) e, concomitantemente, sobrecarregá-las com projetos a analisar, de praticamente todas as éreas do conhecimento humano, pode ter uma conseqüência grave bem concreta, qual seja, a ausência de fiscalização dos projetos em que se impõe um acompanhamento de perto. Nesse sentido, parece paradoxal o Estado brasileiro pretender proteger todas as pessoas de alguma forma envolvidas em pesquisas científicas contra todas e quaisquer possíveis ameaças aos seus direitos fundamentais e acabar por desprotegê-las, face aos estudos científicos de risco, como as pesquisas clínicas. Ao Estado brasileiro cabe, se existe o elemento de risco mais elevado para outros bens ou direitos fundamentais que justifiquem uma intervenção estatal, definir qual o regime jurídico aplicável às pesquisas clínicas (e não para todas as pesquisas que envolvem, em termos amplos e gerais).

A discussão no legislativo ainda é incipiente e esteve por vezes centrada em buscar a tutela penal. Sabe-se que proteger direitos fundamentais é uma tarefa bastante árdua, tarefa esta que requer pensar adequados níveis de proteção, em um intervalo entre dois limites extremos: nem acima de um nível máximo de proteção jurídica, nem abaixo ou aquém de um limite mínimo de proteção jurídica. Decidir quem decide, decidir quais são os procedimentos e sob quais critérios materiais, bem como decidir quem fiscaliza, assim como decidir quais as sanções aplicáveis no caso de descumprimento da lei.

\section{REFERÊNCIAS}

ALEXY, Robert. Teoria de los derechos fundamentales. Madrid: Centro de Estudios Constitucionales, 1997.

ALEXY, Robert. Epílogo a la teoria de los derechos fundamentales. Revista Española de Derecho Constitucional, ano 22, n. 66, Sept.-Dic. 2002.

BRASIL. Ministério da Saúde, Departamento de Ciência e Tecnologia, Secretaria de Ciência, Tecnologia e Insumos Estratégicos. Registro Brasileiro de Ensaios Clínicos (Rebrac): fortalecimento da gestão de pesquisa clínica no Brasil. Revista de Saúde Pública, v. 43, n. 2 , p. 388 , abr. 2009.

BRASIL. REBEC. Registro Brasileiro de Ensaios Clínicos. Disponível em: <www.ensaiosclinicos.gov.br>. Acesso em: 25 mar. 2010. 
CANARIS, Claus-Wilhelm. Direitos fundamentais e Direito privado. Coimbra: Almedina, 2003.

CANOTILHO, José Joaquim Gomes. Direito constitucional e Teoria da constituição. 7. ed. Coimbra: Almedina, 2004.

CHIERICE, Gilberto Orivaldo, PIAI, Dair Bicudo, QUAGLIATO JÚNIOR, Reinaldo.

ASMA NO ADULTO - SUPLEMENTAÇÃO ALIMENTAR COM ÔMEGA-3 E FOSFOETANOLAMINA EM PACIENTES COM ASMA BRÔNQUICA. Anais do XXXIV Congresso Brasileiro de Pneumologia e Tisiologia 2008. Jornal Brasileiro de Pneumologia. ISSN 1806-3713. Disponível em

<http://www.jornaldepneumologia.com.br/PDF/Suple_1_1_1SBPT_FINAL.pdf. Acesso em: nov. 2015.

CLOTET. Joaquim. O consentimento informado nos Comitês de Ética em pesquisa e na prática médica: conceituação, origens e atualidade. Bioética, v. 3, n. 1, 1995.

CLOTET, Joaquim. Bioética com ética aplicada e genética. Bioética, v. 5, n. 2, 1997.

GOLDIM, José Roberto. O consentimento informado e a adequação de seu uso na pesquisa em seres humanos. Tese (Doutorado em Medicina), Programa de Pós-Graduação em Medicina da Universidade Federal do Rio Grande do Sul, Porto Alegre, 1999.

INPI - nova metodologia de síntese da fosfoetanolamina na forma

Sólida com cálcio, magnésio e zinco e na forma de solução com

Monoetanolamina. PI 0800460-9 A2. Disponível em

$<$ https://gru.inpi.gov.br/pePI/servlet/PatenteServletController?Action=detail\&CodPedido=760

350\&SearchParameter $=$ PI08004609a2> Acesso em

nov. 2015.

LUZ, Ilana Martins. A criminalização dos ensaios clínicos com seres humanos: carência e dignidade de tutela ou expansionismo penal? Revista Direito UNIFACS, n. 176, fevereiro 2015. Disponível em: <http://www.revistas.unifacs.br/index.php/redu/article/view/3473/0> . Acesso em: 25 nov. 2015.

MIRANDA, Jorge. Manual de direito constitucional. 3. ed. Tomo IV. Coimbra: Editora Coimbra, 2000.

PETTERLE, Selma Rodrigues. A informação sobre pesquisas envolvendo seres humanos no Brasil: do SISNEP à Plataforma Brasil. In: Direitos fundamentais e democracia I [Recurso eletrônico on-line] organização CONPEDI/UNINOVE; Coordenadores: Ednilson Donisete Machado, Marcelo Andrade Cattoni de Oliveira. - Florianópolis : FUNJAB, 2013. Disponível em: < http://www.publicadireito.com.br/artigos/?cod=24988d9aa627ea72>.

PINTO, Paulo Mota. Direitos de Personalidade no Código Civil Português e no novo Código Civil Brasileiro. Revista da AJURIS, Porto Alegre: Ajuris, v. 31, n. 96, dez. 2004.

PINTO, Paulo Mota. O Direito ao Livre Desenvolvimento da Personalidade. In: PortugalBrasil Ano 2000. Coimbra: Editora Coimbra, 1999.

PLS 323/1991 - iniciativa do Senado Federal (Senador Francisco Rollemberg). Arquivado em 13/03/1995.Disponível em: < http://www25.senado.leg.br/web/atividade/materias/- 
/materia/31117>. Acesso em: 18 jan. 2015.

PLS 25/1992 - iniciativa do Senado Federal (Senador César Dias). Arquivado em 13/03/1995.Disponível em: <http://www25.senado.leg.br/web/atividade/materias//materia/24812>. Acesso em: 18 jan. 2015.

PL 7.086/2002 - iniciativa da Câmara dos Deputados (Deputado Ivan Paixão). Arquivado em 31/01/2003. Disponível em: < http://www2.camara.leg.br/proposicoesWeb/fichadetramitacao?idProposicao=63954>. Acesso em: 18 jan. 2015.

PL 2.473/2003 - iniciativa da Câmara dos Deputados (Deputado Colbert Martins). Arquivado em 31/01/2011.Disponível em: < http://www2.camara.leg.br/proposicoesWeb/fichadetramitacao?idProposicao=142406 >. Acesso em: 18 jan. 2015.

PL 3.497/2004 - iniciativa da Câmara dos Deputados (Deputado Ivan Valente e Deputada Maninha). Aguarda constituição de Comissão Especial para emitir Parecer em 07/03/2012.Disponível em:

<http://www2.camara.leg.br/proposicoesWeb/fichadetramitacao?idProposicao=252103>. Acesso em: 18 jan. 2015.

PL 6.032/2005 - iniciativa do Poder Executivo. Apensado ao PL-3497/2004 em 17/10/2005. Disponível em:

<http://www2.camara.leg.br/proposicoesWeb/fichadetramitacao?idProposicao=302782 >. Acesso em: 18 jan. 2015.

PLS 78/2006 - iniciativa do Senado Federal (Senador Cristóvão Buarque). Arquivado em 23/12/2014. Disponível em: < http://www25.senado.leg.br/web/atividade/materias//materia/77271>. Acesso em: 18 jan. 2015.

PLS 396/2007 - iniciativa do Senado Federal (Senador Flávio Arns). Arquivado em 07/01/2011. Disponível em: < http://www25.senado.leg.br/web/atividade/materias//materia/81743>. Acesso em: 18 jan. 2015.

PL 2.173/2015 - iniciativa da Câmara dos Deputados (Deputado Celso Jacob). Na Comissão de Constituição e Justiça e de Cidadania em 09/07/2015.

Disponível em:

<http://www2.camara.leg.br/proposicoesWeb/fichadetramitacao?idProposicao=1548901>. Acesso em: 18 jan. 2015.

PLS 200/2015 - iniciativa do Senado Federal (Senadora Maria Amélia e outros). Pronto para a pauta na Comissão de Ciência, Tecnologia, Inovação, Comunicação e Informática 16/12/2015, com substitutivo. Disponível em: <http://www25.senado.leg.br/web/atividade/materias/-/materia/120560>. Acesso em: 18 jan. 2015.

PL 3.454/2015 - iniciativa da Câmara dos Deputados (Deputado Welinton Prado). Na Comissão de Seguridade Social e Família em 23/11/2015.Disponível em: < http://www2.camara.leg.br/proposicoesWeb/fichadetramitacao?idProposicao=2025544>. Acesso em: 18 jan. 2015.

PULIDO, Carlos Bernal. El principio de proporcionalidad y los derechos fundamentales: el principio de proporcionalidad como criterio para determinar el contenido de los derechos 
fundamentales vinculante para el legislador. Madrid: Centro de Estudios Políticos y Constitucionales, 2003.

SARLET, Ingo Wolfgang. Constituição e Proporcionalidade: o direito penal e os direitos fundamentais entre proibição de excesso e de insuficiência. Revista Brasileira de Ciências Criminais, n. 47, p. 98, mar.-abr. 2004.

SARLET, Ingo Wolfgang. A eficácia dos direitos fundamentais: uma teoria geral dos direitos fundamentais na perspectiva constitucional. 10. ed. rev. atual e ampl. Porto Alegre: Livraria do Advogado, 2009.

SARLET, Ingo Wolfgang, PETTERLE, Selma Rodrigues. Dignidade da Pessoa Humana e o Direito Fundamental à Identidade Genética. Cadernos UHI Idéias. v. 8, n. 128 (2010). Também disponível em: <http://www.ihu.unisinos.br/cadernos/index.php/ihuideias/issue/viewIssue/251/pdf_127>.

SCHWABE, Jürgen. Cincuenta Años de Jurisprudencia del Tribunal Constitucional Federal Alemán. Traducción de Marcela Anzola Gil. Colombia: Gustavo Ibáñez, 2003.

SISNEP Efeito da suplementação alimentar com ácido graxo ômega-3 e fosfoetanolamina em pacientes com asma brônquica. CAAE - 0224.0.146.000-07. UNICAMP/Faculdade de Ciências Médicas - SP. 2007. Disponível em http://portal2.saude.gov.br/sisnep/pesquisador/extrato_projeto.cfm?codigo=134105. Acesso em: 30 nov. 2015.

STRECK, Lenio Luiz. Da proibição de excesso (Übermassverbot) à proibição de proteção deficiente (Untermassverbot): de como não há blindagem contra normas penais

inconstitucionais. Revista do Instituto de Hermenêutica Jurídica, Porto Alegre: Instituto de Hermenêutica Jurídica, v. I, n. 2, 2004.

TEPEDINO, Gustavo. A Tutela da personalidade no Ordenamento Civil-constitucional Brasileiro. In: Temas de Direito Civil. $2^{a}$ ed, revista e atualizada. Rio de Janeiro: Renovar, 2001. 